\title{
Cardio-Respiratory Manifestations and Its Correlation with Clinical Disease Activity Index in Rheumatoid Arthritis

\author{
Preeti Yadav ${ }^{1 *}$, Sushama Jotkar ${ }^{2}$
}

${ }^{1}$ Postgraduate Student, Department of Medicine, D. Y. Patil Medical College, Hospital and Research Institute, Kolhapur, Maharashtra, India

${ }^{2}$ Professor, Department of Medicine, D. Y. Patil Medical College, Hospital and Research Institute, Kolhapur, Maharashtra, India

DOI: $10.36347 /$ sasjm.2020.v06i11.005

| Received: 11.11.2020 | Accepted: 21.11.2020 | Published: 25.11.2020

*Corresponding author: Preeti Yadav

Abstract

Original Research Article

Background: In Rheumatoid arthritis (RA), disease activity helps to achieve remission with appropriate treatment, also known as treat-to-target strategy. This strategy is controversial as composite indexes assessing disease activity clinically may be affected by comorbidities or other patient-related factors. Thus they may not truly be a representation of disease activity. The study aimed to assess the cardio-respiratory manifestation and its correlation with clinical disease activity index (CDAI) in RA patients. Methodology: The cross-sectional study was performed on 100 RA patients. Severity of RA was assessed using CDAI. Cardiovascular manifestations were investigated using Electrocardiogram (ECG), 2D Echocardiography (M-mode). Chest X-ray, high resolution computed tomography of the chest, and pulmonary function tests were performed to assess respiratory manifestations. Data were analysed using R-Studio V1.2.5001 software. Chi-square test was used to find the association between variables. Results: Abnormal ECG findings were observed in 17 patients whereas, cardiovascular and respiratory abnormality was observed in 78 and 44 patients respectively. High and moderate diseases activity was found in 42 and 58 patients respectively. A significant association was observed between duration of disease and, cardiac and respiratory manifestation $(\mathrm{P}=0.0009, \mathrm{P}=0.0004)$. A significant difference was observed in CDAI of patients with or without respiratory abnormalities $(\mathrm{P}=0.044)$. No significant association was found between CDAI and cardiorespiratory abnormality. Conclusion: Most RA patients had cardiorespiratory manifestations with high and moderate CDAI. For early identification and treatment, screening of cardiorespiratory manifestation is required.

Keywords: Electrocardiography, Echocardiography, Respiratory function test, Rheumatoid arthritis, Tomography.

Copyright $\odot 2020$ The Author(s): This is an open-access article distributed under the terms of the Creative Commons Attribution 4.0 International License (CC BY-NC 4.0) which permits unrestricted use, distribution, and reproduction in any medium for non-commercial use provided the original author and source are credited.

\section{INTRODUCTION}

Rheumatoid arthritis (RA) is a chronic inflammatory disease characterized by synovial and systemic inflammation and presence of auto-antibodies [1]. RA is heterogeneous and may be described as a syndrome with different causes including genetic and environment related factors resulting in clinical manifestations [2]. Although joint pain is the main feature, RA has a plethora of extraarticular manifestations which causes substantial morbidity and mortality [3]. Traditional risk factors of cardiovascular disease (CVD) namely hyperlipidemia, diabetes mellitus and positive CVD family history along with BMI are considered risk factors for CVD in RA patients. However, these traditional risk factors fail to explain the higher likelihood of CVD in RA patients [4]. Also, RA patients with high rheumatoid factor titres are more likely to have extra articular manifestations
[5]. Respiratory involvement in seen in $30-40 \%$ of RA patients [6].

However, there is paucity of data regarding cardio-respiratory manifestation in RA patients and its association with clinical disease activity index (CDAI). Therefore, the study was conducted to assess cardiorespiratory manifestations and its correlation with CDAI in RA patients.

\section{MATERIAL AND METHODS}

The cross-sectional study was performed on 100 RA patients attending the medicine outpatient department of tertiary care centre. 100 patients included were based on active disease, age $>18$ years and diagnosed based on 2010 ACR/EULAR classification criteria [7]. Patient with malignancy, pregnancy were excluded from the study. Severity of RA was assessed using CDAI. Cardiovascular manifestations were investigated using Electrocardiogram (ECG), 2D 
Echocardiography (M-mode). Chest X-ray, high resolution computed tomography of the chest, and pulmonary function tests were performed to assess respiratory manifestations. Data were analysed using RStudio V1.2.5001 software. Chi-square test was used to find the association between variables.

\section{RESULTS}

The average age was $51.93 \pm 14.2$ years, of which $52 \%$ were females. According to Kuppuswamy classification most of the patients were of the upper lower class $(n=34)$. The average duration of disease and CDAI was $4.78 \pm 3.60$ years and $25.94 \pm 9.28$ respectively. Duration of disease and CDAI of patients are summarized in table 1. ECG, cardiac and respiratory findings of patients are shown in table 2. Duration of RA was significantly associated with cardiovascular manifestations and respiratory manifestations $(\mathrm{P}=0.0009$ and $\mathrm{P}=0.0004)$. PASP $(\mathrm{n}=6)$, ejection fraction $<60 \% \quad(n=10)$, left ventricular hypertrophy $(n=20)$, and regional wall motion abnormality $(n=17)$ was observed in patients.

The pulmonary function test showed mean FVC $80 \pm 11.31 \mathrm{~L}$, FEV1/FVC ratio $76.62 \pm 10.81 \%$, PFER 87.31 $\pm 9.40 \mathrm{~L} / \mathrm{s}$, and CIMT $0.92 \pm 0.27$. No significant difference was observed in FEV1, FEV1/FVC, and PEFR of patients with or without respiratory abnormalities however, a significant difference was observed in CDAI value in patient with respiratory abnormality $(23.66 \pm 6.47)$ and patients without respiratory abnormality (27.74 \pm 10.72$)$ $(\mathrm{P}=0.044)$. No significant difference was observed in CDAI values of patients with the presence of cardiovascular abnormality when compared with CDAI values of patients without abnormalities. No significant association was between CDAI and cardiorespiratory abnormality.

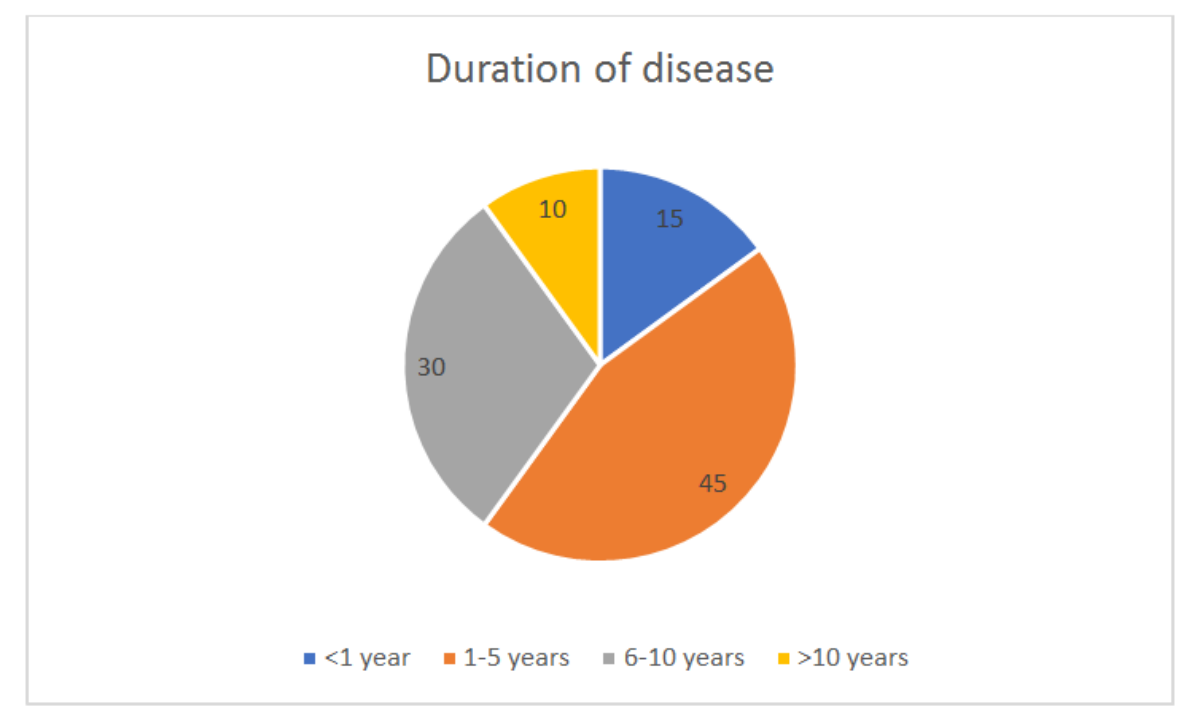

Graph-1: Duration of disease and CDAI of patients

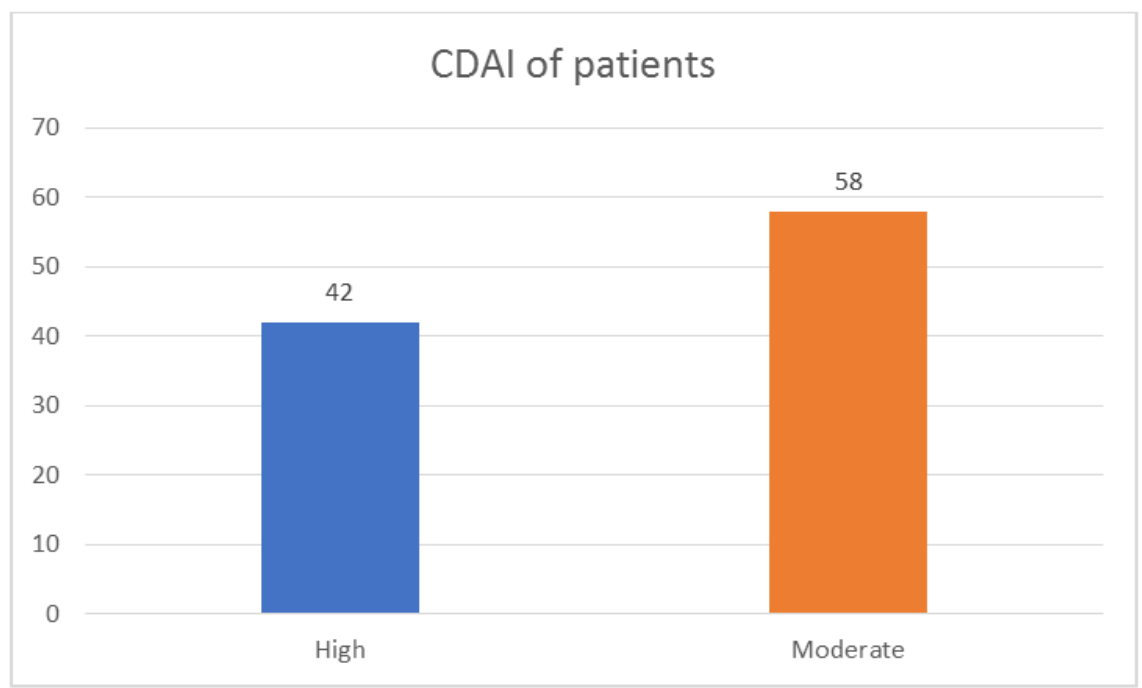

Graph-2: CDAI of patients 
Table-1: ECG, cardiac and respiratory findings

\begin{tabular}{|l|l|}
\hline ECG findings & Number of patients \\
\hline RBBB & 4 \\
\hline ST-T Changes & 5 \\
\hline Left ventricular hypertrophy & 6 \\
\hline Premature Ventricular Contraction & 2 \\
\hline Cardiac Finding & Number of patients \\
\hline LV diastolic dysfunction & 6 \\
\hline Myocardial infarction & 14 \\
\hline Heart failure & 7 \\
\hline Hypertension & 16 \\
\hline Pericardial effusion & 9 \\
\hline Pulmonary hypertension & 16 \\
\hline Valvular abnormalities & 3 \\
\hline Pericarditis & 7 \\
\hline Respiratory finding & Number of patients \\
\hline Pulmonary nodule & 3 \\
\hline Pleural effusion & 10 \\
\hline Pulmonary Fibrosis & 19 \\
\hline Bronchiectasis & 8 \\
\hline Interstitial lung disease & 4 \\
\hline
\end{tabular}

\section{DISCUSSION}

The proportion of females was higher than males and the average age of the patients was $51.93 \pm 14.2$, with a mean $4.78 \pm 3.60$ years of disease duration. These findings was comparative to previous studies [8-10]. Prabhakaran AP et al., had a high CDAI score in $60 \%$ of their cases. However, their mean CDAI score was similar to ours [11].

ECG findings showed similar results as by the study of Singh $\mathrm{R}$ et al., In contrast with the results the study of Singh $\mathrm{R}$ et al., showed LV diastolic dysfunction, and pericardial effusion as common cardiovascular findings. Whereas, pulmonary hypertension was observed in $1.67 \%$ patients [9]. The study of Dawson JK showed PASP in $31 \%$ patients, abnormal ejection fraction in $9 \%$ patients [12] AlAssadi et al., reported a mean FVC of $78.55 \pm 30.43$ [13] and Madhavan et al., reported a mean FVC of 86.3 $\pm 9.88 \mathrm{~L}$ and FEV1/FVC was $96.54 \pm 13.29 \%$ [14]. Banik et al., also found pulmonary findings in Ra to be associated with duration of the disease [15]. The study of Kroot E et al., showed about $27 \%$ of patients with at least one chronic coexisting disease [16].

\section{CONCLUSION}

In this study significant difference was observed in CDAI of patients with or without pulmonary manifestations. Duration of RA was significantly associated with cardiorespiratory manifestation. No significant association was observed between CDAI and cardiorespiratory manifestation. Hence, screening of cardiorespiratory manifestation in patients with RA is required for early identification and treatment.

\section{REFERENCES}

1. Scott DL, Wolfe F, Huizinga TW. Rheumatoid arthritis. Lancet. 2010; 376:1094-108.

2. Chemin K, Klareskog L, Malmstrom V. Is rheumatoid arthritis an autoimmune disease? Curr Opin Rheumatol. 2016; 28(2):181-8.

3. Esposito AJ, Chu SG, Madan R, Doyle TJ, Dellaripa PF. Thoracic manifestations of rheumatoid arthritis. Clin Chest Med. 2019 Sep 1;40(3):545-60.

4. Jagpal A, Navarro-Millán I. Cardiovascular comorbidity in patients with rheumatoid arthritis: a narrative review of risk factors, cardiovascular risk assessment and treatment. BMC Rheumatol. 2018 Dec 1;2(1):10.

5. Cojocaru M, Cojocaru IM, Silosi I, Vrabie CD, Tanasescu R. Extra-articular manifestations in rheumatoid arthritis. Maedica. 2010 Dec; 5(4):286.

6. Alunno A, Gerli R, Giacomelli R, Carubbi F. Clinical, epidemiological, and histopathological features of respiratory involvement in rheumatoid arthritis. Biomed Res Int. 2017 Jan 1;2017.

7. Funovits J, Aletaha D, Bykerk V, Combe B, Dougados M, Emery P, Felson D, Hawker G, Hazes JM, Huizinga T, Kay J. The 2010 American College of Rheumatology/European League Against Rheumatism classification criteria for rheumatoid arthritis: methodological report phase I. Ann Rheum Dis. 2010 Sep 1;69(9):1589-95

8. Dhaon P, Das SK, Srivastava R, Dhakad U. Performances of Clinical Disease Activity Index (CDAI) and Simplified Disease Activity Index (SDAI) appear to be better than the gold standard Disease Assessment Score (DAS- 28- CRP) to assess rheumatoid arthritis patients. Int $\mathrm{J}$ Rheum Dis. 2018;21(11):1933-9. 
9. Singh R, Kaur C, Sibia P, Singh B, Chaudhary A. Study of Cardiovascular Manifestations of Rheumatoid Arthritis and Correlation with Disease Duration and Severity. IOSR-JDMS. 2018:17(2):35-9.

10. Masooleh IS, Zayeni H, Haji-Abbasi A, Azarpira M, Hadian A, Hassankhani A, Parsa BG. Cardiac involvement in rheumatoid arthritis: A crosssectional study in Iran. Indian Heart J. 2016;68(3):332-5.

11. Prabhakaran AP, Periyasamy R, Nandini R. Cardiovascular Profile of Rheumatoid Arthritis Patients and its Correlation with Disease Activity. Int J Sci Stud 2020;8(1):63-67.

12. Baqir M, Ryu JH. The Non-ILD Pulmonary Manifestations of RA. Lung Disease in Rheumatoid Arthritis. Humana Press, Cham. 2018;163-173.
13. Al-Assadi T, Al-Shemery A, Salman S. Correlation of Lung Function with Disease Activity Rheumatoid Arthritis. Oman Med J. 2009;24(2):84.

14. Madhavan S, Kingsley CT, Anandan H. Correlation of Pulmonary Function with Rheumatoid Arthritis Disease Activity. International journal of contemporary medical research. 2017;4(9):2000-3.

15. Banik S, Tapadar SR, Ray A, Chaudhuri AD. A Study on Pulmonary Manifestations of Rheumatoid Arthritis. J Clin Diagn Res. 2018 Jun 1;12(6):5-9.

16. Kroot EJ, van Gestel AM, Swinkels HL, Albers MM, van de Putte LB, van Riel PL. Chronic comorbidity in patients with early rheumatoid arthritis: a descriptive study. J Rheumatol. 2001;28(7):1511-7. 